\title{
An investigation of ionospheric disturbances over South Africa during the magnetic storm on 15 May 2005
}

\author{
C. M. Ngwira ${ }^{1,2}$, L. A. McKinnell ${ }^{1,2}$, P. J. Cilliers ${ }^{2}$, E. Yizengaw ${ }^{3}$, and B. D. L. \\ Opperman $^{2}$ \\ ${ }^{1}$ Department of Physics and Electronics, Rhodes University, Grahamstown, South Africa \\ ${ }^{2}$ Hermanus Magnetic Observatory, Hermanus, South Africa \\ ${ }^{3}$ Institute of Scientific Research, Boston College, Boston, USA
}

\begin{abstract}
The effects of the 15 May 2005 severe geomagnetic storm on the South African ionosphere are studied using ground-based and satellite observations. Ionospheric disturbances have less frequently been investigated over mid-latitude regions. Recently, a number of studies investigated their evolution and generation over these regions. This paper reports on the first investigation of travelling ionospheric disturbances (TIDs) over mid-latitude South Africa. Using Global Positioning System (GPS)-derived total electron content (TEC) variations from the South African network of dual frequency GPS receivers, we were able to examine the effects of the disturbance on the quiet-time TEC. Two TEC enhancements were observed at low- and mid-latitudes: the first observed between $30-45^{\circ} \mathrm{S}$ geomagnetic latitudes associated with equatorward neutral winds and the passage of a TID, and the second TEC enhancement associated with a second TID. In addition, the F-region critical frequency (foF2) values observed at two ionosonde stations show that the ionospheric response as seen by ionosondes was different from that of the TEC response during the disturbance period. The dissimilarity between the TEC and the foF 2 suggests that two competing drivers existed, i.e., the westward electric field and equatorward neutral wind effects.
\end{abstract}

Key words: Ionosphere, ionospheric disturbances, total electron content, travelling ionospheric disturbances.

\section{Study of ionospheric disturnances over South Africa}

A number of studies of the ionosphere utilising GPS observational data across South Africa have also been documented (e.g, Cilliers et al., 2004; Moeketsi et al., 2007; Opperman et al., 2007; McKinnell et al., 2007). More recently, neural network techniques have been applied in the modelling of electron content over South Africa (e.g, Habarulema et al., 2009, 2010, and references therein). Although there have been many observations of TIDs using different techniques (see e.g, Hocke and Schlegel, 1996; Nicolls et al., 2004; Ding et al., 2007; Tsugawa et al., 2007; Lynn et al., 2008, and references therein), none have ever been reported over South Africa.

This paper presents a study of the response of the ionosphere to the major magnetic storm event of 15 May 2005, with a focus on the first observation of TIDs over mid-latitude locations within South Africa. In the study, we present observations of ionospheric perturbations using GPS-derived TEC measurements. Two TEC enhancements were observed at mid-latitudes during the daytime in the African sector. Using multi-instrument observations, it is shown that 
the first observed TEC enhancement between $30-45^{\circ} \mathrm{S}$ geomagnetic latitudes was associated with equatorward neutral winds and the passage of a TID, and that the second TEC enhancement was associated with a second TID. In addition, the F-region critical frequency (foF2) values observed at two ionosonde stations show that the ionospheric response as seen by ionosondes was different from that of the TEC response during the disturbance period. The dissimilarity between the TEC and the foF 2 suggests that two competing drivers existed, i.e., the westward electric field and equatorward neutral wind effects.

\section{References}

Cilliers, P. J., Opperman, B. D. L., Mitchell, C. N., Spencer, P. J., 2004. Electron density profiles determined from tomographic reconstruction of total electron content obtained from GPS dual frequency data; first results from the South African network of dual frequency GPS receiver stations. Advances in Space Research 34, 2049-2055.

Ding, F., Wan, W., Ning, B., Wang, M., 2007. Large-scale traveling ionospheric disturbances observed by GPS total electron content during the magnetic storm of 29-30 October 2003. Journal of Geophysical Research 112, A06309, doi:10.1029/2006JA012013.

Habarulema, J. B., McKinnell, L. A., Cilliers, P. J., Opperman, B. D. L., 2009. Application of neural networks to South African GPS TEC modelling. Advances in Space Research 43, $1711-1720$.

Habarulema, J. B., McKinnell, L. A., Opperman, B. D. L., 2010. TEC measurements and modelling over Southern Africa during magnetic storms; a comparative analysis. Journal of Atmospheric and Solar-Terrestrial Physics 72, 509-520.

Hocke, K., Schlegel, K., 1996. A review of atmospheric gravity waves and traveling ionospheric disturbances. Annales Geophysicae 14, 917-940.

Lynn, K. J. W., Gardiner-Garden, R., Sjarifudin, M., Terkildsen, M., Shi, J., Harris, T. J., 2008. Large-scale travelling atmospheric disturbances in the night ionosphere during the solarterrestrial event of 23 May 2002. Journal of Atmospheric and Solar-Terrestrial Physics 70, $2184-2195$.

McKinnell, L. A., Opperman, B., Cilliers, P. J., 2007. GPS TEC and ionosonde TEC over Grahamstown, South Africa: First comparisons. Advances in Space Research 39, 816-820.

Moeketsi, D. M., Combrinck, W. L., McKinnell, L., Fedrizzi, M., 2007. Mapping GPS-derived total electron content over Southern Africa during different epochs of solar cycle 23. Advances in Space Research 39, 821-829.

Nicolls, M., Kelley, M. C., Coster, A. J., González, S. A., Makela, J. J., 2004. Imaging the structure of a large-scale TID using ISR and TEC data. Geophysical Research Letters 31, L09812, doi:10.1029/2004GL019797.

Opperman, B. D. L., Cilliers, P. J., McKinnell, L. A., Haggard, R., 2007. Development of a Regional GPS-based ionospheric TEC model for South Africa. Advances in Space Research $39,808-815$.

Tsugawa, T., Otsuka, Y., Coster, A. J., Saito, A., 2007. Medium-scale traveling ionospheric disturbances detected with dense and wide TEC maps over North America. Geophysical Research Letters 34, L22101, doi:10.1029/2007GL031663. 